\title{
Heparin-induced Thrombocytopenia in Pediatrics Following Cardiopulmonary Bypass
}

\author{
Shi-Min Yuan \\ Division of Cardiac Surgery, Department of Cardiothoracic Surgery, The First Hospital of Putian, Teaching Hospital,
} Fujian Medical University, Putian, Fujian Province, China

\begin{abstract}
Heparin-induced thrombocytopenia (HIT) is an immune-mediated response to heparin administration. HIT following cardiopulmonary bypass (CPB) procedures has not been clearly delineated in pediatric populations. By comprehensive retrieval of the pertinent literature published since 2000, 19 reports were collected with 33 pediatric patients recruited into this study. A female predominance was noted in this patient setting. HIT occurred after a mean heparin exposure of 2.8 times. Pediatric HIT following CPB showed different features from that with no CPB, by a longer span on postoperative day 1-16, and a significant negative correlation between the platelet count and time of occurrence of thrombocytopenia on postoperative day 1-8. The thrombus formation developed on postoperative day 13. Heparin discontinuation and use of coganulant substitute are the important treatments of choice. In HIT patients, continued heparin use may cause patient death or recurrence of HIT. HIT-related thrombosis was present in $69.6 \%$ of the patients with similar incidence rates of arterial and venous thrombosis; and the thrombosis could be managed by medical, surgical or device explant methods. The direct thrombin inhibitors lepirudin, argatroban and bivalirudin as well as the factor Xa inhibitor danaparoid can be used safely in most of the pediatric patients. The event-free survival rate of this patient setting was $69.7 \%$.
\end{abstract}

Key Words: Cardiopulmonary bypass, Heparin, Thrombocytopenia, Thrombosis.

How to cite this article: Yuan SM. Heparin-induced thrombocytopenia in pediatrics following cardiopulmonary bypass. J Coll Physicians Surg Pak 2019; 29(10):986-92.

\section{INTRODUCTION}

Heparin-induced thrombocytopenia (HIT) is an immunemediated response to heparin administration that promotes antibody-mediated platelet activation with a high risk of thrombotic complications. ${ }^{1}$ HIT type I is a benign, with a transient drop in platelets by $40-50 \%$ with no more sequelae; whereas, HIT type II patients develop an immune-mediated thrombocytopenia, which leads to thromboembolic complications in $>50 \%$ of the patients. ${ }^{2}$ HIT is an intensely procoagulant disorder; and in adult cardiac surgery, patients carry both significant thrombotic morbidity $(38-81 \%)$ and mortality $(28 \%) .{ }^{3}$ HIT is defined as a relative reduction of platelet count of $50 \%$ that develops within 5-14 days after heparin exposure. 4 In this article, HIT referred to HIT type II.

Unfractionated heparin (UFH) is immunogenic, and heparin-dependent antibodies may appear on postoperative day (POD) $5-10$ in $25-50 \%$ of adult patients under-going a cardiac operation. A minority (1-3\%) of the patients may have strongly activated platelets presenting with thrombocytopenia and excessive thrombin production,

Correspondence to: Shi-Min Yuan, Division of Cardiac Surgery, Department of Cardiothoracic Surgery, The First Hospital of Putian, Teaching Hospital, Fujian Medical University,

Putian 351100, Fujian Province, China

E-mail: shiminyuan@126.com

Received:January 18, 2019; Revised: March 15, 2019;

Accepted: March 15, 2019 if UFH use sustains $>1$ week. ${ }^{3}$ Thrombocytopenia is a major manifestation leading to the suspicion of HIT. ${ }^{3}$ Detection of HIT-antibodies is necessary when there is a significant reduction of platelet counts, or, unexplained platelet count reduction to $<100,000$ platelets $\mu \mathrm{L}$ $(100 \times 109 / \mathrm{L})$, new thromboembolic complications during heparin use, skin reactions at the heparin injection site, or systemic reactions after heparin exposure. 5

HIT in children have been increasingly reported. 4 The prevalence of HIT was $0.058 \%$ and that of HIT with thrombosis was $0.046 \%$ in pediatric patients on UFH. ${ }^{6}$ HIT seems to be uncommon in pediatric patients, and those receiving cardiac surgery under cardiopulmonary bypass (CPB) are at an increased risk. ${ }^{7}$ The clinical features and management of HIT following procedures have not been clearly delineated in pediatric populations. In order to highlight the clinical aspects of HIT, following $\mathrm{CPB}$ and the alike procedures (including extracorporeal life support, extracorporeal membrane oxygenation, and ventricular assist device) in pediatric patients, a systematic review is made herewith.

\section{METHODOLOGY}

The Preferred Reporting Items for Systematic Reviews and Meta-analyses (PRISMA) statement guidelines were followed in this meta-analysis. 8 Publications were systematically searched in the PubMed, Highwire Press, and the Cochrane Library databases since January 
2000 throughout August 2018. The MeSH terms and keywords used to identify articles included HIT, cardiac surgical procedures, cardiopulmonary bypass, extracorporeal life support, extracorporeal membrane oxygenation, ventricular assist device, heparin, unfractionated heparin, low molecular weight heparin, antiheparin platelet factor 4 antibody, particle gel immunoassay, and heparin-induced platelet activation assay, with a filter of pediatrics. The screening of the bibliographic references helped in completing the literature retrieval. Fifty-eight articles were found related to the topic and keywords in the literature search; and 19 articles, which met the inclusion and exclusion criteria during preliminary assessment, were included in the review. The exclusion criteria were unrelated to pediatric HIT following CPB $(n=28)$, pediatric HIT developing before CPB $(n=5)$, adult HIT following CPB $(n=5)$, and HIT in pediatris with no CPB procedure $(n=1)$.

The data independently extracted from each study were the study population, demographics, clinical diagnosis, surgical procedures, time of occurrences of HIT events, therapeutic strategies and effects, and patients' outcomes.

The measurement data were expressed in mean \pm standard deviation and compared by independent sample t-test. The categorical variables were presented as frequency with percentage and were compared by Fisher exact test. The platelet count and time of occurrence of thrombocytopenia was also tested by linear correlation. $p<0.05$ was considered statistically significant.

\section{RESULTS}

A total of 19 reports were collected with 33 pediatric patients recruited into this study.2,7,9-25 Patients were at the age of $3.0 \pm 0.5$ years $(n=32)$. Patients' gender was not stated for 2 cases. For the remaining 30 cases, 18 $(60 \%)$ were males and $12(40 \%)$ were females $\left(\chi^{2}=2.4\right.$, $p=0.196)$. Patients' ages showed no difference between male and female patients ( $3.7 \pm 3.2$ years vs. $1.6 \pm 2.5$, $t=1.861, p=0.075$ ).

In 2 patients, the diagnosis was not given, but it was described as bridging to lung transplantation, 23 and for reoperation after previous mitral valve replacement, 24 respectively. In the remaining 31 patients, the most common diagnosis was hypoplastic left heart syndrome (Table I). Fontan procedure was the most common operation performed before the development of HIT (Table II).

Heparin exposure was described in 27 patients. In one patient it was described as several times, 11 and thus it was excluded from the statistical analysis. The heparin exposure of the remaining 26 patients were $2.8 \pm 1.8$ times $(n=25)$.

HIT and thrombosis: Postoperative platelet count was reported in 26 patients with 33 measurements with a mean of $50.1 \pm 29.1 \times 109 / L \quad(n=33)$, which occurred on
POD $7.4 \pm 4.4$. The correlation between the platelet count and time of occurrence of thrombocytopenia was not significant $(r=-0.0224, p=0.454)$. It indicated that there were two stages of thrombocytopenia: the first was concentrated on POD 1-8 and the second appeared on

Table I: Clinical diagnosis of cardiovascular disorders in 31 patients with heparin-induced thrombocytopenia.

\begin{tabular}{ll}
\hline Diagnosis & $\mathrm{n}(\%)$ \\
\hline HLHS & $9(29.0)$ \\
DORV & $3(9.6)$ \\
TOF + PA & $2(6.5)$ \\
TOF & $2(6.5)$ \\
DILV & $2(6.5)$ \\
Complex CHD & $2(6.5)$ \\
Complete AV canal defect & $2(6.5)$ \\
Unbalanced AV canal & $1(3.2)$ \\
TOF + AV canal defect & $1(3.2)$ \\
TGA & $1(3.2)$ \\
TA + PA & $1(3.2)$ \\
Shone anomaly, on ECMO & $1(3.2)$ \\
Hypoplastic RV, D-TGA, pulmonary valve stenosis & $1(3.2)$ \\
Hypoplastic RV & $1(3.2)$ \\
DIRV & $1(3.2)$ \\
Worsening hypoxia & $1(3.2)$ \\
\hline AV:Atroventicuar;AR:Aotic valvereplacenent CHD: Congental heatt
\end{tabular}

AV: Atrioventricular; AVR: Aortic valve replacement; CHD: Congenital heart defect; D: Dextro; DILV: Double inlet left ventricle; DIRV: Double inlet right ventricle; DORV: Double outlet right syndrome; PA: Pulmonary atresia; V: Right ventricle; TA: Tricuspid atresia; TGA: Transposition syndrome; PA: Pulmonary atresia; $V$ : Right ventric
of the great arteries; TOF: Tetralogy of Fallot.

Table II: Surgical procedures before the development of heparin-induced thrombocytopenia in 33 patients.

\begin{tabular}{ll}
\hline Surgical procedure & $\mathrm{n}(\%)$ \\
\hline Fontan, fenestrated & $6(18.2)$ \\
ECMO & $3(9.1)$ \\
Fontan, unspecified & $2(6.1)$ \\
Norwood & $2(6.1)$ \\
TOF repair & $2(6.1)$ \\
BCPC takedown + Rastalli procedure & $1(3.0)$ \\
2nd left ventricular Berlin Heart VAD implant & $1(3.0)$ \\
AV canal repair & $1(3.0)$ \\
Bidirectional Glenn procedure + repair of anomalous pulmonary return & $1(3.0)$ \\
Debanding + AV canal repair & $1(3.0)$ \\
ECLS & $1(3.0)$ \\
Fontan, lateral caval tunneled + ECMO & $1(3.0)$ \\
Fontan, nonfenestrated & $1(3.0)$ \\
Konno procedure + AVR & $1(3.0)$ \\
Norwood, modified & $1(3.0)$ \\
Norwood + CPB changed to VAD & $1(3.0)$ \\
Norwood + VAD & $1(3.0)$ \\
Rastelli procedure & $1(3.0)$ \\
Rastelli procedure + VSD closure & $1(3.0)$ \\
Repair for unbalanced AV canal, mitral valve stenosis, aortic valve & $1(3.0)$ \\
stenosis, coarctation of the aorta & \\
TOF/AV canal defect repair & $1(3.0)$ \\
TOF/PA repair & $1(3.0)$ \\
TVR (a reversed 21-mm St. Jude HP aortic valve) for severe & $1(3.0)$ \\
tricuspid insufficiency and a 5-mm ascending aorta-to-SVC & \\
Gore-Tex shunt for inadequate pulmonary blood flow & \\
\hline AV: Atrioventricular; AVR: Aortic valve replacement; BCPC: Bidirectional cavo-pulmonary \\
connection; CPB: Cardiopulmonary bypass; ECLS: Extracorporeal life support; ECMO: \\
Extracorporeal membrane oxygenation; HP: Hemodynamic Plus series; PA: Pulmonary \\
atresia; SVC: Superior vena cava; TOF: Tetralogy of Fallot; TVR: Tricuspid valve replacement; \\
VAD: Ventricular assist device; VSD: Ventricular septal defect. & \\
& \\
&
\end{tabular}


Table III: Locations of thrombosis formation in 23 patients.

\begin{tabular}{|c|c|}
\hline Location of thrombosis & $\mathrm{n}(\%)$ \\
\hline Device & $10(43.5)$ \\
\hline CRRT catheter 12 & $1(10)$ \\
\hline CVVH line, innominate \& distal IVC, lung \& ECMO circuit 18 & $1(10)$ \\
\hline Distal extremities \& ECMO circuit 13 & $1(10)$ \\
\hline ECLS circuit \& venous reservoir of the CPB circuit 17 & $1(10)$ \\
\hline ECMO circuit 23 & $1(10)$ \\
\hline Fontan canal, disseminated thrombi \& ECMO circuit 21 & $1(10)$ \\
\hline $\begin{array}{l}\text { Extracardiac conduit, deep vein thromboses (right common } \\
\text { femoral \& external iliac veins) }{ }^{16}\end{array}$ & $1(10)$ \\
\hline PICC of the thigh 7 & $1(10)$ \\
\hline Pulmonary embolism \& dialysis line 7 & $1(10)$ \\
\hline Inlet valve 11 & $1(10)$ \\
\hline Shunt/tunnel & $4(17.4)$ \\
\hline Rastelli shunt ${ }^{7}$ & $1(25)$ \\
\hline Norwood shunt \& leg7 & $1(25)$ \\
\hline Fontan tunnel 14 & $1(25)$ \\
\hline Right femoral artery \& Fontan canal-right PA 21 & $1(25)$ \\
\hline Vessel & $8(34.8)$ \\
\hline IVC \& right iliac vein 22 & $1(12.5)$ \\
\hline Left brachial \& right femoral arteries 20 & $1(12.5)$ \\
\hline Left femoral artery 22 & $1(12.5)$ \\
\hline Left PA \& SVC ${ }^{10}$ & $1(12.5)$ \\
\hline Pulmonary vein 7 & $1(12.5)$ \\
\hline Right atrium 15 & $1(12.5)$ \\
\hline SVC7 & $1(12.5)$ \\
\hline Small arteries of the low extrimities 25 & $1(12.5)$ \\
\hline Organ & $1(4.3)$ \\
\hline Lungs \& kidneys 2 & $1(100)$ \\
\hline
\end{tabular}

CPB: Cardiopulmonary bypass; CRRT: Continuous renal replacement therapy; $\mathrm{CVVH}$ : Continuous venovenous hemofiltration; ECLS: Extra-corporeal life support; ECMO: Extracorporeal membrane oxygenation; IVC: Inferior vena cava; PA: Pulmonary artery; PICC: Peripherally inserted central catheter; SVC: Superior vena cava.

POD 14-16. During POD 9-13, no patient developed HIT. However, a significant negative correlation was found between the platelet count and time of occurrence of thrombo-cytopenia during POD 1-8 $(r=0.5893, p=0.001)$.

In $22(66.7 \%)$ patients, 25 positive diagnostic tests for confirmation of HIT were reported: a positive antiheparin platelet factor 4 antibody in 15 (60\%) cases, 2,9,11-13,15-20,22-25 on POD $6.8 \pm 4.1(n=5), 2,18,21,22$ a positive particle gel immunoassay in $5(20 \%)$ patients on POD $9.0 \pm 4.2$ $(n=4)$, and a positive heparin-induced platelet activation assay in $5(20 \%)$ patients on POD $11.8 \pm 5.7(n=4) .21,22,24$

Of the patient setting, $10(30.3 \%)$ patients did not have thrombosis, whereas $23(69.7 \%)$ patients did $\left(\chi^{2}=10.2\right.$, $p=0.003) .7,9,14,19,21,24$ The sites of thrombosis formation of the 23 patients were listed in Table III. Most occurred in the device circuit, followed by in the human vessels with more in the vein than in the arteries but lack of statistical significance $[60 \%(6 / 10)$ vs. $40 \%$ (4/10), $\left.\chi^{2}=0.8, p=0.656\right)$. The formation time of 8 thromboses of 6 patients were on POD $13 \pm 7.5(n=8) .12,13,16,18,21,22$

In $7 / 33(21.2 \%)$ patients, one or more organ failure developed: renal failure in $3 / 7(42.9 \%)$ patients, ${ }^{11,18}$ heart failure in $1 / 7(14.3 \%)$ patient, 13 heart and renal failure in $2 / 7(28.6 \%)$ patients, 2,12 and multisystem organ failure in $1 / 7(14.3 \%)$ patient. 22
Treatment: Discontinuation of heparin was described in 25 patients. In 1 (4\%) patient, heparin was not stopped and the patient eventually died of HIT.7 In the remaining $24(96 \%)$ patients, heparin was discontinued after diagnosis of HIT. Heparin/UFH was used in $22(91.7 \%)$ patients and low molecular weight heparin $(\mathrm{LMWH})$ and heparin in $2(8.3)$ patients $\left(\chi^{2}=33.3, p<0.001\right) .17,21$ Time of discontinuation of heparin was $7.4 \pm 4.3$ days after the operation $(n=21)$. The treatment of HIT lasted for 16.8 \pm 15.2 days $(n=12) .12-14,16,17,21-24$ A substitute anticoagulant was not used in $3(9.1 \%)$ patients. ${ }^{7,22}$ In the remaining $30(90.9 \%)$ patients, argatroban was the most commonly used substitute anticoagulant followed by bivalirudin (Table IV). The administration of these substitute anticoagulants included bolus, continuous infusion, CPB priming, and catheterisation, etc. Statistical analyses showed that there were no significant differences between the commonly used substitute anticoagulants and heparin in terms of target activated partial thromboplastin time and activated clotting time.

Left ventricular assisted device or extracorporeal life support was used in four (12.1\%) patients, ${ }^{11,16-18}$ and extracorporeal membrane oxygenation was instituted in five $(15.6 \%)$ patients. $7,13,18,21,25$

Outcomes: Twenty-three $(69.7 \%)$ patients were eventfree survivors, $7,9,10,12-17,20-22,24,25$ one (3.0\%) patient was HIT-recurrent, ${ }^{19}$ and nine (27.3\%) patients died. Of the deceased patients, seven (77.8\%) died of HIT,2,7,11,18,21,22 and two $(22.2 \%)$ died of non-HIT,21,23 with one of them died of sudden bradycardia. ${ }^{21}$ In the recurrent patient, the platelet count decreased significantly following reoperation and second reoperation with the use of tirofiban and heparin. Anticoagulation with lepirudin was started on day 3 after second reoperation and coumadin was started on day 6 . On day 10 , the platelet count had recovered. ${ }^{19}$

In HIT patients, continued heparin use may cause patient death, ${ }^{7}$ or recurrence of HIT. ${ }^{19}$ But in one patient, heparin use even after HIT caused no problem. ${ }^{19}$

Treatment of HIT was not mentioned in 11 (33.3\%) patients. In the remaining $22(66.7 \%)$ patients, heparin discontinuation with the use of substitute anticoagulant was applied in 16 (72.7\%) patients, 2,9,11,12,14-16,19-21,23,25 heparin discontinuation in $4(18.2 \%), 10,13,22$ use of substitute anticoagulant (bivalirudin) in $1(4.5 \%),{ }^{21}$ and multiple platelet transfusions in $1(4.5 \%)$ patient. 17 In the above 16 patients, the substitute anticoagulants were bivalirudin $(n=6), 9,20,21,23$ tirofiban with subsequent lepirudin, ${ }^{19}$ lepirudin $(n=3), 12,15,16$ argatroban $(n=4), 2,14,25$ antiplatelet $(n=1),{ }^{11}$ and fondaparinux $(n=1) .{ }^{7}$ In one of them, tirofiban failed to increase the activated partial thromboplastin time to the target value. ${ }^{19}$ The treatment of thrombosis revealed a success in $11 / 16(68.8 \%)$ patients and a failure in $5 / 16(31.3 \%)$ patients $\left(\chi^{2}=4.50\right.$, $p=0.076$, Table V). 
Table IV: Anticoagulant effects in 30 patients.

\begin{tabular}{|c|c|c|c|c|}
\hline Substitute anticoagulant & Administration & Dose & Rate & Time course \\
\hline Argatroban $(n=13)$ & $\begin{array}{l}\text { Infusion }(n=13)^{7,8,13,14,17,18,25} \\
\text { Bolus }(n=2)^{17,18} \\
\text { Catheterisation }(n=5)^{7} \\
\text { CPB }(n=2)^{7,17} \\
\text { ECMO }(n=2)^{7} \\
\text { Unspecified }(n=1)^{2}\end{array}$ & $\begin{array}{l}4,500 \mu \mathrm{g}(250 \mu \mathrm{g} / \mathrm{kg}) \text { for extracorporeal } \\
\text { life support circuit thrombosis }{ }^{17} \\
200 \mu \mathrm{g} / \mathrm{kg}^{18} \\
800 \mu \mathrm{g}(45 \mu \mathrm{g} / \mathrm{kg})^{17}\end{array}$ & $1-7.5 \mu \mathrm{g} / \mathrm{kg} / \mathrm{min}^{8,14,17,18,25}$ & $\begin{array}{l}\text { 4-10 days } 13,14 \text { argatroban infusion was } \\
\text { discontinued } 25 \text { minutes before the } \\
\text { end of CPB } 17\end{array}$ \\
\hline Bivalirudin $(n=10)$ & $\begin{array}{l}\text { Bolus }(n=4)^{8,10,13,20} \\
\text { Infusion }(n=6)^{8,10,13,20,21} \\
\text { CPB }(n=3)^{8,13,21} \\
\text { Unspecified }(n=4)^{21,23}\end{array}$ & $\begin{array}{l}0.75-1.5 \mathrm{mg} / \mathrm{kg}^{8,20} \\
50 \mathrm{mg}^{8}\end{array}$ & $\begin{array}{l}1.75-4.5 \mathrm{mg} / \mathrm{kg} / \mathrm{hour} 8,20 \\
4.2-67 \mu \mathrm{gg} / \mathrm{kg} / \mathrm{min}^{13}\end{array}$ & $\begin{array}{l}\text { Prior to operation } 8 \\
14-24 \text { days }^{21} \\
14 \text { days }^{23}\end{array}$ \\
\hline Lepirudin $(\mathrm{n}=5)$ & $\begin{array}{l}\text { Bolus }(n=2)^{11,16} \\
\text { Infusion }(n=3)^{11,15,16} \\
\text { CPB }(n=1)^{16} \\
\text { Systemic anticoagulation }(n=1)^{12} \\
\text { Unspecified }(n=1)^{24}\end{array}$ & $\begin{array}{l}1.2 \mathrm{mg} 11 \\
0.2 \mathrm{mg} / \mathrm{kg}^{16}\end{array}$ & $\begin{array}{l}0.15 \mathrm{mg} / \mathrm{kg} / \text { hour (lepirudin } \\
\text { was discontinued } 4 \text { hours } \\
\text { later due to lung \& gut } \\
\text { bleeding) }{ }^{11} \\
0.1 \mathrm{mg} / \mathrm{kg} / \mathrm{hour} \text { decreased } \\
\text { to } 0.08 \mathrm{mg} / \mathrm{kg} / \text { hour }^{16} \\
5.5-46 \mu \mathrm{g} / \mathrm{kg} / \text { hour }^{12}\end{array}$ & $\begin{array}{l}\text { Start on day } 7 \text { for } 8 \text { days }{ }^{16} \\
\text { Start on day } 20 \text { for } 6 \text { weeks }{ }^{12} \\
7 \text { days } 24\end{array}$ \\
\hline Tirofiban $(n=1)$ & $\begin{array}{l}\text { Bolus }(n=1)^{19} \\
\text { Infusion }(n=1)^{19}\end{array}$ & $10 \mu \mathrm{g} / \mathrm{kg}^{19}$ & $0.15 \mu \mathrm{g} / \mathrm{kg} / \mathrm{min}^{19}$ & \\
\hline Fondaparinux $(n=1)$ & $\begin{array}{l}\text { Subcutaneous injection }(n=1)^{21} \\
\text { Unspecified }(n=1)^{7}\end{array}$ & & & 1 month 22 days 21 \\
\hline Aspirin $(n=1)$ & Oral7 & & & \\
\hline Warfarin $(n=4)$ & Oral 10,13,15,21 & & & \\
\hline Acenocoumarol $(n=1)$ & Oral20 & & & \\
\hline Phenprocoumon $(n=1)$ & Oral24 & & & \\
\hline
\end{tabular}

CPB: Cardiopulmonary bypass; ECMO: Extracorporeal membrane oxygenation; UFH: Unfractionated heparin.

\section{DISCUSSION}

The clinical and diagnostic features of HIT type II in this pediatric population were similar to adults. 25 The incidence of HIT was documented to be $2.3-3.7 \%$ in pediatric patients where $1-3 \%$ were following cardiac operation with the use of UFH.26 The median platelet nadir was 58 (range, 27-191) $\times 109 / \mathrm{L}$, and thrombosis occurred a median of 10 (range, 5-45) days after the start of heparin therapy. ${ }^{27}$ Klenner et al. summarized literature information and proposed that the most frequent manifestation of HIT was platelet count reduction $(58 / 69,84.1 \%) .28$ HIT was associated with thromboembolic complications in $48 / 69(69.6 \%)$ patients.

Takemoto et al. reported that, in adults with HIT, 30-60\% had thrombosis at the time of clinical diagnosis and venous events were more common than arterial. ${ }^{29}$ Similarly, most thrombotic events reported in pediatric patients appeared to be venous rather than arterial; perhaps in part due to a decreased incidence of atherosclerosis in pediartrics. A clinical study on a large patient population revealed predominance of venous thrombosis (2.4:1), with pulmonary embolism in $40 \%$ of the patients. In contrast, post-cardiac surgical patients showed predominance of arterial thrombosis (1:8.5), and the prevalence of arterial thrombosis (limb artery thrombosis >thrombotic stroke >myocardial infarction) was opposed to that in the non-HIT patient population. The HIT-related thrombosis presented on the same day more common than before the day of platelet count reduction (59.8\% vs. $33.5 \%)$. In adults, orthopedic / trauma surgery and the degree of platelet count reduction were the most important risk factors for thrombosis. ${ }^{5}$ Schmugge et al. reported that the calculated incidence of pediatric HIT-associated thrombosis was $2.3 \%$, at a similar prevalence with adults. ${ }^{30}$ Schmugge et al. noted that, of their 14 patients with HIT-associated thrombosis, $9(64.3 \%)$ were from the veins, $2(14.3 \%)$ from the arteries, and $3(21.4 \%)$ from both the artery and the vein. None of their patients died or required amputation. 30

In adults, the risk of developing HIT is influenced by the patient population (surgical >medical), the type of heparin (bovine >porcine, UFH >LMWH >fondaparinux), the dose (therapeutic >prophylactic >heparin flushes), the route of administration (intravenous >subcutaneous), the duration of administration (higher with 4 or more days), and patient gender (female $>$ male). ${ }^{26}$ The risk of 
Table V: Treatment of thrombosis in 16 patients.

\begin{tabular}{|c|c|c|c|c|}
\hline Treatment & $\mathrm{n}$ & Successful & Failed & Remark of the failed case \\
\hline Device exchange & 3 & 3 & 0 & \\
\hline $\begin{array}{l}\text { Extracorporeal life support circuit change and } \\
\text { argatroban infusion }\end{array}$ & 117 & 1 & 0 & \\
\hline Berlin heart explant & 111 & 1 & 0 & \\
\hline Catheter removal & 112 & 1 & 0 & \\
\hline Medical treatment & 9 & 5 & 4 & \\
\hline Argatroban & 2 & 114 & 113 & Failed (6-fold increased dose failed) \\
\hline Bivalirudin & 2 & 123 & 121 & $\begin{array}{l}\text { Disseminated thrombi formation despite } \\
\text { effective anticoagulation with bivalirudin, } \\
\text { repeatedly clotting the extracorporeal } \\
\text { membrane oxygenation circuit }\end{array}$ \\
\hline Lepirudin & 1 & 115 & 0 & \\
\hline Aspirin & 1 & 17 & 0 & \\
\hline Warfarin & 1 & 0 & 116 & Suspected thrombosis at 3 months \\
\hline Tissue-type plasminogen activator & 1 & 0 & 118 & $\begin{array}{l}\text { Tissue-type plasminogen activator } \\
\text { discontinued due to bleeding }\end{array}$ \\
\hline $\begin{array}{l}\text { AngioJet thrombolysis for pulmonary } \\
\text { artery thrombosis }\end{array}$ & 1 & 110 & 0 & \\
\hline Surgical treatment & 4 & 3 & 1 & \\
\hline $\begin{array}{l}\text { Thrombectomy (thrombus extended through } \\
\text { the entire length of the inferior vena cava } \\
\text { to the level of the Fontan connection) }\end{array}$ & 1 & 0 & 122 & Died in operating room \\
\hline Thrombectomy (Fontan \& pulmonary arteries) & 1 & 121 & 0 & \\
\hline $\begin{array}{l}\text { Thromboembolectomy (left brachial \& right } \\
\text { femoral arteries), below elbow amputation of } \\
\text { the left forearm and right forefoot }\end{array}$ & 1 & 120 & 0 & \\
\hline $\begin{array}{l}\text { Thrombectomy (Fontan and pulmonary arteries } \\
\text { thrombectomy) }\end{array}$ & 1 & 122 & 0 & \\
\hline
\end{tabular}

children developing HIT was related to the extent of UFH exposure, and the most frequent HIT in children was due to prolonged UFH exposure or higher cumulative doses of UFH. 26 The contribution of the extracorporeal membrane oxygenation circuit to thrombocytopenia was noted.25 Half children were antibody-positive after reexposure to UFH in reoperations, whereas only $1.3 \%$ developed clinical HIT. ${ }^{31}$ This proportion was similar to that of adults undergoing cardiac surgery in which $27-50 \%$ of patients showed a positive platelet factor 4 antibody, and $1-2 \%$ developed clinical HIT.26 Late thrombocytopenia was related to a combination of factors (operation severity, degree of hypothermia during $\mathrm{CPB}$, prolonged use of UFH, and milrinone). ${ }^{32}$

The clinical diagnosis of HIT is based on platelet count reduction by $>50 \%$ from baseline within 4-14 days after heparin therapy; with or without thrombosis or bleeding; or positive heparin-dependent antibodies. ${ }^{26}$ However, for some patients, the lowest platelet count can be within the normal range. Thus, a more accurate indicator of HIT is platelet count reduction of $>50 \%$ from baseline. HIT should be suspected in pediatrics with normal platelet counts with thrombosis of unknown origin. Moreover, a positive platelet factor 4 antibody does not necessarily lead to the diagnosis of HIT, as this may occur transiently in $27-50 \%$ of the adult patients, and recover to normal after a median of 50 days. 33

If pediatric HIT is left untreated, $42 \%$ would show poor outcomes, whereas the prevalence of those with poor outcomes would decrease to $18 \%$ when a substitute anticoagulant is used.25 Any time HIT is suspected, discontinuation of heparin should be strongly considered and confirmatory diagnostic testing should be performed. ${ }^{29}$ Early recognition of HIT type II is vital because withdrawal of all forms of heparin is the first and most important aspect of therapy. ${ }^{25}$ Clinical strategy now avoids heparin exposure for patients positive for antiheparin platelet factor 4 antibody who are potentially at risk of developing HIT.33

The reported treatment regimens are very heterogeneous. 28 In the presence of thrombosis, anticoagulation for the thrombotic event is generally recommended as, at least 3 months for deep vein thrombosis, and 3-6 months for pulmonary embolism. 29

The direct thrombin inhibitors lepirudin, argatroban and bivalirudin as well as the factor $\mathrm{Xa}$ inhibitor danaparoid have been used with success for treatment of HIT in children. Both bivalirudin and argatroban have short half-lives and both have been studied for pediatric use. 29 Bivalirudin has been shown to be effective in cardiac surgery with and without CPB. ${ }^{26}$ Argatroban is cleared hepatically, whereas bivalirudin is primarily proteolyzed in the plasma.29 It is highly specific in its ability to irreversibly bind to both the catalytic and enzymatic sites of thrombin. But contraindications to lepirudin were found for anticoagulation on CPB in patients with renal and coagulation disorders. Lepirudin has a longer halflife than bivalirudin and argatroban, and is cleared 
renally, ${ }^{29}$ and hemofiltration or hemodialysis should be performed in patients with renal dysfunctions. ${ }^{33}$ Danaparoid treatment of pediatric HIT patients has been reported, but in adults, intraoperative clotting and postoperative bleeding often occurred. ${ }^{26}$ Fondaparinux is an indirect inhibitor of $\mathrm{Xa}$, and it has also been applied in pediatrics. ${ }^{29}$ All agents, regardless of its metabolic pathway, displayed similar bleeding incidences, and none seemed to carry a greater risk. 26

Pediatric HIT is often associated with a hypercoagulable state, carrying the risk of thrombus formation. Except for venous thrombosis, arterial occlusions and stroke occurred. Limb amputation was necessary in $4 \%$ of pediatric patients with HIT, and $11.6 \%$ (8/69) died. Pouplard et al. stated that, if LMWH are used instead of UFH post-cardiac surgery in adults, the incidence of HIT would be reduced. ${ }^{31}$ As in younger children, HIT seems to occur following cardiac operation, the postoperative use of LMWH should be further investigated. Substitution of UFH by LMWH whenever possible is most likely to be effective in decreasing the risk of HIT in pediatrics. ${ }^{28} \mathrm{In}$ HIT infants, pretreatment with epoprostenol sodium before heparin reexposure may offer a safe and effective anticoagulation for CPB. ${ }^{34}$

A novel finding of this study was a two-staged occurrence of HIT following CPB procedures, on POD 1-8 and on $P O D$ 14-16. In the first stage, a significant negative correlation was found between the platelet count and time of occurrence of thrombocytopenia. UFH was more commonly used and caused more chances of HIT than LMWH. During the treatment of HIT, the adverse effect of the substitute anticoagulants was only seen in one patient, in whom lepirudin was used, but discontinued 4 hours later, due to lung and gut bleeding. ${ }^{11}$ In another patient, tirofiban failed to increase the activated partial thromboplastin time to the target value. ${ }^{19}$ There were three choices to treat HIT-related thrombosis: surgical, medical or device exchange. No significant differences were found in terms of the success rates between the three choices.

\section{CONCLUSION}

Pediatric HIT following CPB showed different features from that with no CPB, by a longer span on POD 1-16, and a significant negative correlation between the platelet count and time of occurrence of thrombocytopenia on POD 1-8. Heparin discontinuation and use of coganulant constitute are the important treatments of choice. In HIT patients, continued heparin use may cause patient death or recurrence of HIT. HIT-related thrombus could be managed by medical, surgical or device explant methods. The direct thrombin inhibitors lepirudin, argatroban and bivalirudin as well as the factor Xa inhibitor danaparoid can be used safely in most of the pediatric patients.

\section{CONFLICT OF INTEREST:}

Author declared no conflict of interest.

\section{AUTHOR'S CONTRIBUTION:}

SMY: Substantial contribution to the conception and design of the work; the acquisition, analysis, and interpretation of data for the work; drafting the work and revising it critically for important intellectual content; final approval of the version to be published; and agreement to be accountable for all aspects of the work in ensuring that questions related to the accuracy or integrity of any part of the work are appropriately investigated and resolved.

\section{REFERENCES}

1. Warkentin TE, Kelton JG. Heparin-induced thrombocytopenia. Hematol/oncol Clin North Am 1997; 17:325-41.

2 Martchenke J, Boshkov L. Heparin-induced thrombocytopenia in neonates. Neonatal Netw 2005; 24:33-7.

3. Alsoufi B, Boshkov LK, Kirby A, Ibsen L, Dower N, Shen I, et al. Heparin-induced thrombocytopenia (HIT) in pediatric cardiac surgery: An emerging cause of morbidity and mortality. Semin Thorac Cardiovasc Surg Pediatr Card Surg Annu 2004; 7: 155-71.

4. Avila ML, Shah V, Brandão LR. Systematic review on heparininduced thrombocytopenia in children: A call to action. $J$ Thromb Haemost 2013; 11:660-9.

5. Greinacher A, Völpel H, Janssens U, Hach-Wunderle V, Kemkes-Matthes B, Eichler $\mathrm{P}$, et al. Recombinant hirudin (lepirudin) provides safe and effective anticoagulation in patients with heparin-induced thrombocytopenia: A prospective study. Circulation 1999; 99:73-80.

6. Obeng EA, Harney KM, Moniz T, Arnold A, Neufeld EJ, Trenor CC. Pediatric heparin-induced thrombocytopenia: prevalence, thrombotic risk, and application of the 4Ts scoring system. J Pediatr 2015; 166:144-50.

7. Boshkov LK, Kirby A, Shen I, Ungerleider RM. Recognition and management of heparin-induced thrombocytopenia in pediatric cardiopulmonary bypass patients. Ann Thorac Surg 2006; 81: S2355-9.

8. Liberati A, Altman DG, Tetzlaff J. The PRISMA statement for reporting systematic reviews and meta-analyses of studies that evaluate healthcare interventions: Explanation and elaboration. J Clin Epidemiol 2009; 62:e1-34.

9. Argueta-Morales IR, Olsen MC, DeCampli WM, Munro HM, Felix DE. Alternative anticoagulation during cardiovascular procedures in pediatric patients with heparin-induced thrombocytopenia. J Extra Corpor Technol 2012; 44:69-74.

10. Breinholt JP, Moffett BS, Texter KM, Ing FF. Successful use of bivalirudin for superior vena cava recanalization and stent placement in a child with heparin-induced thrombocytopenia. Pediatr Cardiol 2008; 29:804-7.

11. Eghtesady P, Nelson D, Schwartz SM, Wheeler D, Pearl JM, Cripe $\mathrm{LH}$, et al. Heparin-induced thrombocytopenia complicating support by the Berlin Heart. ASAIO J 2005; 51:820-5.

12. Hanke CA, Barth K, Nakamura L, Budde U, Arnold R, Zieger B, et al. Lepirudin treatment in a boy with suspected HIT II after surgery because of tetralogy of Fallot. Hamostaseologie 2009; 29:168-70. 
13. Almond CS, Harrington J, Thiagarajan R, Duncan $C N$, LaPierre R, Halwick D, et al. Successful use of bivalirudin for cardiac transplantation in a child with heparin-induced thrombocytopenia. J Heart Lung Transplant 2006; 25:1376-9.

14. Hofer A, Heschl M, Leitner-Peneder G, Meier J. Argatroban as an alternative anticoagulant in the case of heparin-induced thrombocytopenia after pediatric cardiac surgery. J Clin Exp Cardiolog 2015; 6:1000408.

15. Iannoli ED, Eaton MP, Shapiro JR. Bidirectional glenn shunt surgery using lepirudin anticoagulation in an infant with heparin-induced thrombocytopenia with thrombosis. Anesth Analg 2005; 101:74-6.

16. Knoderer CA, Knoderer HM, Turrentine MW, Kumar M. Lepirudin anticoagulation for heparin-induced thrombo-cytopenia after cardiac surgery in a pediatric patient. Pharmacotherapy 2006; 26:709-12.

17. Latham GJ, Jefferis Kirk C, Falconer A, Dickey R, Albers EL, McMullan DM. Challenging argatroban management of a child on extracorporeal support and subsequent heart transplant. Semin Cardiothorac Vasc Anesth 2016; 20:168-74.

18. Mejak B, Giacomuzzi C, Heller E, You X, Ungerleider R, Shen I, et al. Argatroban usage for anticoagulation for ECMO on a post-cardiac patient with heparin-induced thrombocytopenia. J Extra Corpor Technol 2004; 36:178-81.

19. Neuray M, Balling G, Schreiber C, Martin K. Two consecutive open heart operations in a small child with heparin-induced thrombocytopenia type II using anticoagulation with heparin and tirofiban. Ann Thorac Surg 2012; 94:653-5.

20. Pantula NR, Vedula K. Catastrophic complication following heparin therapy. Asian Cardiovasc Thorac Ann 2014; 22:1096-8.

21. Pollak U, Mishaly D, Kenet G, Vardi A. Heparin-induced thrombocytopenia complicating children after the Fontan procedure: Single-center experience and review of the literature. Congenit Heart Dis 2018; 13:16-25.

22. Porcelli R, Moskowitz BC, Cetta F, Graham LC, Godwin JE, Eidem BW, et al. Heparin-induced thrombocytopenia with associated thrombosis in children after the Fontan operation: report of two cases. Tex Heart Inst J 2003; 30:58-61.

23. Preston TJ, Dalton HJ, Nicol KK, Ferrall BR, Miller JC, Hayes D. Plasma exchange on venovenous extracorporeal membrane oxygenation with bivalirudin anticoagulation. World $\mathrm{J}$ Pediatr Congenit Heart Surg 2015; 6:119-22.
24. Schreiber C, Dietrich W, Braun S, Kostolny M, Eicken A, Lange R. Use of heparin upon reoperation in a pediatric patient with heparin-induced thrombocytopenia after disappearance of antibodies. Clin Res Cardiol 2006; 95:379-82.

25. Scott LK, Grier LR, Conrad SA. Heparin-induced thrombocytopenia in a pediatric patient receiving extracorporeal membrane oxygenation managed with argatroban. Pediatr Crit Care Med 2006; 7:473-5.

26. Vakil NH, Kanaan AO, Donovan JL. Heparin-induced thrombocytopenia in the pediatric population: A review of current literature. J Pediatr Pharmacol Ther 2012; 17:12-30.

27. Dager WE, White RH. Low-molecular-weight heparin-induced thrombocytopenia in a child. Ann Pharmacother 2004; 38: 247-50.

28. Klenner AF, Lubenow N, Raschke R, Greinacher A. Heparininduced thrombocytopenia in children: 12 new cases and review of the literature. Thromb Haemost 2004; 91:719-24.

29. Takemoto CM, Streiff MB. Heparin-induced thrombocytopenia screening and management in pediatric patients. Hematology Am Soc Hematol Educ Program 2011; 2011:162-9.

30. Schmugge $M$, Risch L, Huber AR, Benn A, Fischer JE. Heparin-induced thrombocytopenia-associated thrombosis in pediatric intensive care patients. Pediatrics 2002; 109:E10.

31. Pouplard C, May MA, lochmann S, Amiral J, Vissac AM, Marchand M, et al. Antibodies to platelet factor 4-heparin after cardiopulmonary bypass in patients anticoagulated with unfractionated heparin or a low-molecular-weight heparin: clinical implications for heparin-induced thrombocytopenia. Circulation 1999; 99:2530-6.

32. Ranucci M, Carlucci C, Isgrò G, Brozzi S, Boncilli A, Costa E, et al. Hypothermic cardiopulmonary bypass as a determinant of late thrombocytopenia following cardiac operations in pediatric patients. Acta Anaesthesiol Scand 2009; 53:1060-7.

33. Böning A, Morschheuser T, Bläse U, Scheewe J, von der Brelie M, Grabitz R, et al. Incidence of heparin-induced thrombo-cytopenia and therapeutic strategies in pediatric cardiac surgery. Ann Thorac Surg 2005; 79:62-5.

34. von Heymann C, Hagemeyer E, Kastrup M, Ziemer S, Proquitté $H$, Konertz WF, et al. Heparin-induced thrombo-cytopenia type II in an infant with a congenital heart defect--anticoagulation during cardiopulmonary bypass with epoprostenol sodium and heparin. Pediatr Crit Care Med 2006; 7:383-5. 